\title{
Salivary Anti-PGL IgM and IgA Titers and Serum Antibody IgG Titers and Avidities in Leprosy Patients and Their Correlation with Time of Infection and Antigen Exposure
}

Aparecida T. Nagao-Diass, Thereza Lúcia P. Almeida ${ }^{2}$, Maria de Fátima Oliveira ${ }^{1}$, Rivanda C. Santos ${ }^{1}$, Ana Laura P. Lima ${ }^{2}$ and Márcia Brasil ${ }^{2}$

${ }^{1}$ Department of Clinical Analysis and Toxicology, Faculty of Pharmacy, Federal University of Ceará; ${ }^{2}$ Department of Dermatology, Walter Cantídio Universitary Hospital, Federal University of Ceará; Fortaleza, CE, Brazil

\begin{abstract}
The present work proposed to correlate serum antibody avidity and salivary antibody titers as parameters for time of infection and antigen exposure in a co-hort study evaluating leprosy patients in different periods of treatment. Colorimetric enzyme-immunoassays for salivary antibodies, serum antibody IgG titers and avidities were performed in the samples. Anti-PGL-1 IgA and IgM salivary antibodies were significantly higher in multibacillar (MB-L) patients compared to normal controls $(p<0.05)$, but not when compared to borderline tuberculoid $(B T)$ or to paucibacillar (PB-L) patients ( $>>0.05)$. A good correlation was found between salivary anti-PGL-1 IgA and IgM levels in MB-L patients $(r=0.41, p<0.01)$. Two out of 33 tested saliva samples from patients who had completed the drug regimen treatment presented positive salivary antibodies. Among non-treated patients, samples with low, medium or high serum IgG antibody avidity were found in similar frequencies. In patients under treatment, most of the serum samples showed low or medium IgG antibody avidity. The treated MB-L patients showed medium or high antibody avidity, except for two, who showed very low antibody avidity results. We suggest that salivary anti-PGL antibodies and serum IgG avidity could be useful for the indication of recent exposure or re-exposure to bacteria after chemotherapy.

Key-Words: Anti-PGL-1, avidity, leprosy, salivary antibodies.
\end{abstract}

Leprosy is a chronic infectious disease caused by Mycobacterium leprae, which has predilection to skin and nerves. Although great advances have been made, the disease has not been eradicated [1-4]. The fact that the bacteria have a slow growth rate leads to a long time delay until a person has a positive diagnosis. During this period, the individual is already contagious, since a high number of viable $M$. leprae can be present on nasal surfaces [5]. As the disease diagnosis is based on the microscopic detection of acid-fast bacilli in tissue smears, which requires at least $10^{4}$ organisms per gram of tissue for reliable detection, several serological tests [4,68] and molecular biology tests ${ }^{3}$ have been developed. The phenolic glicolipid PGL-1 is considered to be the only $M$. leprae specific antigen [8]. Anti-PGL-1 is highly specific to leprosy patients [9], it is related to bacterial load, and can be useful for leprosy clinical monitoring [7]. The nasal mucosal surfaces are the main portal of entrance for M. leprae. Consequently, the antigen challenge induces local humoral antibody response, principally IgA and IgM, preceding the immune response in serum [10,11]. The mucosal homing phenomenon explains the presence of anti-PGL-1 antibodies in saliva. Besides the secretory immune response, one aspect that is relevant in infectious diseases is the antibody avidity, which has recently been proposed as a laboratorial parameter to distinguish primary infection, reactivation and re-infection

Received on 21 August 2006; revised 6 February 2007.

Address for correspondence: Dr. Aparecida Tiemi Nagao-Dias. Department of Clinical Analysis and Toxicology. Faculty of Pharmacy Universidade Federal do Ceará. Rua Capitão Francisco Pedro, 1210. Zip code: 60430-370 Fortaleza, Ceará, Brazil. Fax:055-85-4009 8292 Phone: 055-85-4009 8262. E-mail: tiemindi@yahoo.com.br.

The Brazilian Journal of Infectious Diseases 2007;11(2):215-219. (C) 2007 by The Brazilian Journal of Infectious Diseases and Contexto Publishing. All rights reserved. in other diseases $[12,13]$. The purpose of the present work was to analyse anti-PGL-1 salivary antibody titers and serum anti-PGL-1 IgG avidity as parameters for correlation with time of infection and antigen exposure.

\section{Materials and Methods}

Subjects and Samples

The patients $(\mathrm{n}=152)$ included in the project were not treated, under treatment or with completed drug regimen in accordance with the World Health Organization protocol, and were assisted at the Hospital Universitário Walter Cantídio, Fortaleza, Federal University of Ceará. Patients were classified based on clinical findings and on bacterial index (BI), according to the Ridley-Jopling scale [14]. Multibacillar or MB-L group $(n=78)$ included polar lepromatous leprosy and borderline lepromatous leprosy patients; paucibacillar or PB-L group $(n=33)$ included polar tuberculoid leprosy, indeterminate leprosy, and neural leprosy patients. Borderline tuberculoid patients (BT, $n=41$ ) were considered as a separate category based on our observations that antibody titers in these patients were much higher than in PB-L patients. Serum samples from blood donors $(n=105)$ were tested for anti-PGL1 IgG titers and included as normal controls for serum analysis (CT). Fifty serum samples from blood donors were pooled and used as control for the anti-PGL-1 IgG cut-off value. Saliva samples from adult volunteers ( $\mathrm{n}=23$ ) were included as healthy controls for saliva analysis. The project was approved by the Ethical Committee of the Hospital Universitário Walter Cantídio. Serum and unstimulated saliva were obtained from the patients after consent was given.

Salivary Antibody Titers

Briefly, microplates (Costar, Cambridge, USA) were coated with 10 mg/L of PGL-1 (kindly provided by Dr. J.S. Spencer, 
Colorado State University, Fort Collins, USA, through the National Institute of Health contract NO1-AI-25469). Then, the plates were blocked with Tris-3\% BSA, pH 7.0 and incubated with 1:50 dilution of saliva samples during $24 \mathrm{~h}$ at $4^{\circ} \mathrm{C}$. After washing, anti-human IgA and anti-IgM alkalinephosphatase conjugates (Sigma, USA) diluted to $1: 1,000$ were added to the wells. After $2 \mathrm{~h}$ at room temperature, the plates were washed and incubated with a substrate solution, containing $1 \mathrm{mg} / \mathrm{mL}$ of p-nitrophenyl phosphate in $1 \mathrm{M}$ diethanolamine solution and $0.002 \mathrm{M}$ of $\mathrm{MgCl}_{2}$ (pH 9.8). After $100 \mathrm{~min}$, reading was done at $405 \mathrm{~nm}$. The results were expressed by the optical density (OD) of the values minus blank. The cut-off value was considered to be the $97^{\text {th }}$ percentile of the normal range. Results $30 \%$ above the cutoff value were considered to be positive.

\section{Serum Anti-PGL-1 IgG Titers}

Briefly, PGL-1 coated microplates were blocked with 3\% BSA-PBS, $\mathrm{pH}$ 7.4, and incubated with 1:50 dilution of serum samples. After $24 \mathrm{~h}$ at $4^{\circ} \mathrm{C}$, the plates were washed and incubated with 1:1,000 dilution of anti-human IgG-peroxidase conjugate (Sigma, USA). After $1 \mathrm{~h} 30 \mathrm{~min}$ at room temperature, the plates were washed and incubated with a substrate solution containing $0.4 \mathrm{mg} / \mathrm{mL}$ orthophenylenediamine and $\mathrm{H}_{2} \mathrm{O}_{2}$ at $0.01 \%$ of the final concentration in $0.1 \mathrm{M}$ citrate-phosphate buffer, pH 5.0. After $30 \mathrm{~min}$, the color development was interrupted by the addition of $\mathrm{H}_{2} \mathrm{SO}_{4} 2.5 \mathrm{~N}$. Reading was done at $492 \mathrm{~nm}$. The results were expressed by the formula: optical density (OD) mean value from the test sample (minus blank) divided by the OD mean value from the normal human serum pool (minus blank). The cut-off value was considered to be 1.0. Values above 1.3 , which is $30 \%$ above the cut-off value, were considered to be positive. Values below 1.0 were considered negative, and those between 1.1 and 1.2 were considered to be indeterminate.

\section{Serum Anti-PGL-1 IgG Avidity}

The avidity of serum IgG antibodies was determined using potassium thiocyanate (KSCN) to the elution of the bound complexes, as described previously elsewhere [15], with some modifications. PGL-1 coated microplates were incubated with 1:50 dilution of serum samples (only those with positive results for anti-PGL-1 IgG were tested) during $24 \mathrm{~h}$ at $4^{\circ} \mathrm{C}$. After washing, $50 \mu \mathrm{L}$ of $2 \mathrm{M} \mathrm{KSCN}$ were added to the plates. After $30 \mathrm{~min}$ at room temperature, the plates were washed six times and incubated with the conjugate. The results were expressed by the percentage of bound complexes remaining after $2 \mathrm{M}$ KSCN elution.

\section{Statistical Analysis}

Unpaired samples were compared by the non-parametric Mann-Whitney or the Kruskal-Wallis and Dunn's tests. Paired samples were compared by the Wilcoxon or the Friedman's tests. Correlations between paired samples were assessed by the nonparametric Spearman test.

\section{Results}

Salivary Antibody Titers

Salivary anti-PGL-1 IgA and IgM antibodies were significantly higher in MB-L patients compared to the normal controls $(\mathrm{p}<0.05)$, but not with the BT or with PB-L patients $(p>0.05$, Figure 1). A good correlation was found between salivary anti-PGL-1 IgA and IgM levels in MB-L patients $(\mathrm{r}=0.41, \mathrm{p}<0.01)$. Four saliva samples from non-treated patients $(\mathrm{n}=20)$ showed positive titers of salivary anti-PGL-1 IgA and/ or IgM (samples number 1, 3, 4 and 5, Table 1). No correlation was obtained between salivary antibodies and serum antiPGL-1 IgG titers ( $p>0.1$ ). Two out of 33 tested saliva samples from patients who had completed the drug regimen treatment presented positive IgM salivary antibodies (samples number 6 and 0 , Table 1$)$. Two saliva samples from the controls $(n=23)$ presented high levels of anti-PGL1 IgA. These samples were excluded from the study.

\section{Serum Anti-PGL-1 IgG Avidity}

Anti-PGL-1 IgG avidity did not show statistical difference when samples with positive and negative bacterial indexes were compared (Figure 2A, $\mathrm{p}>0.05$ ), nor in the different periods of drug treatment (Figure 2B, $\mathrm{p}>0.1$ ). Poor correlation was observed between anti-PGL-1 IgG titers and avidities ( $\mathrm{r}=0.16$, $\mathrm{p}>0.1$ ). For a better analysis of the results, it was assumed that percentages of complexes bound to the immunoplate above $50 \%$ after KSCN elution were representative of high antibody avidity; between $31 \%$ to $49 \%$, medium avidity, and below 30\%, low avidity. Among non-treated MB-L patients $(\mathrm{n}=11)$, samples with low, medium or high IgG antibody avidity were found in similar frequencies (Table 2). In patients under treatment, most of the samples showed low or medium IgG antibody avidity. Among the treated MB-L patients $(n=16), 8$ samples presented medium avidity and 6 presented high antibody avidity; very few (2 out of 16 samples) showed low serum IgG antibody avidity. Two treated MB-L patients showed very low antibody avidity results (samples number 09 and 10, Tab.1).

\section{Discussion}

The importance of analyzing salivary antibodies originated from the knowledge that the main portal of $M$. leprae entrance is the nasal mucosa. That means that the first place where the local immune response is established against $M$. leprae antigens is the mucosal surface, preceding the immune response in serum. Local immune response is induced in order to prevent the adhesion of bacteria to the mucosal surfaces; however, successful elimination of antigen depends on a balanced immune response [16], which relies on the type of pathogen and on the immune efficacy of the host. Smith et al. [17] suggest that development of mucosal immunity to $M$. leprae may be protective. We doubt this possibility because we have found positive results for anti-PGL IgA and IgM among the leprosy patients. We discovered some positivity in salivary anti-PGL-1 IgA levels among the normal controls 
Figure 1. Salivary anti-PGL-1 IgA and IgM antibodies in leprosy patients and in the controls. The results were expressed by the OD values minus blank. The broken lines represent mean values for each group.

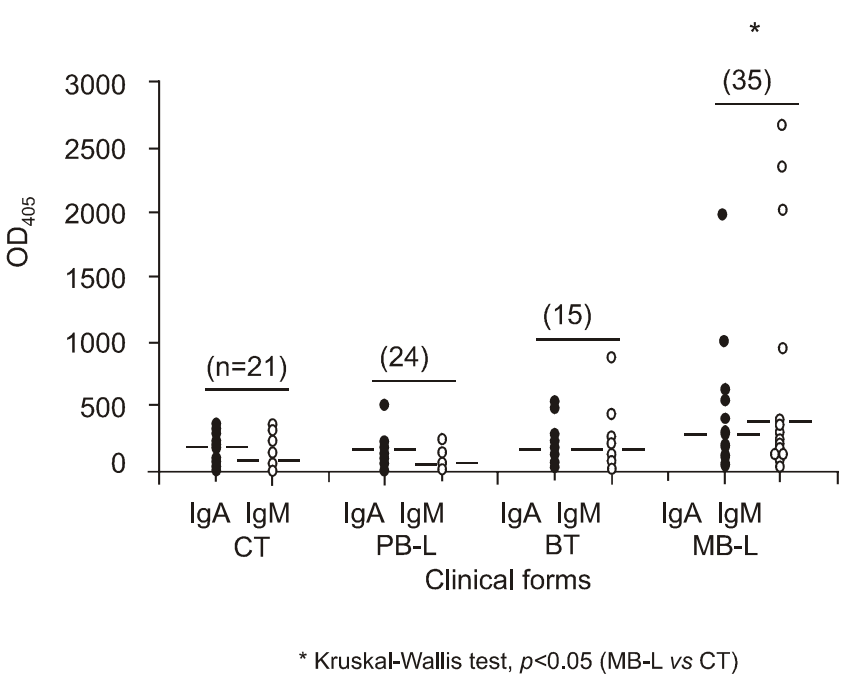

Figure 2. Serum anti-PGL-1 IgG avidity (\%) in leprosy patients according to the bacilloscopy index (A) or to the phases of treatment (B). The dotted lines indicate the antibody avidity range. Avidity-antibodies below 30\% have been considered low, while the ones above $50 \%$ are seen high.
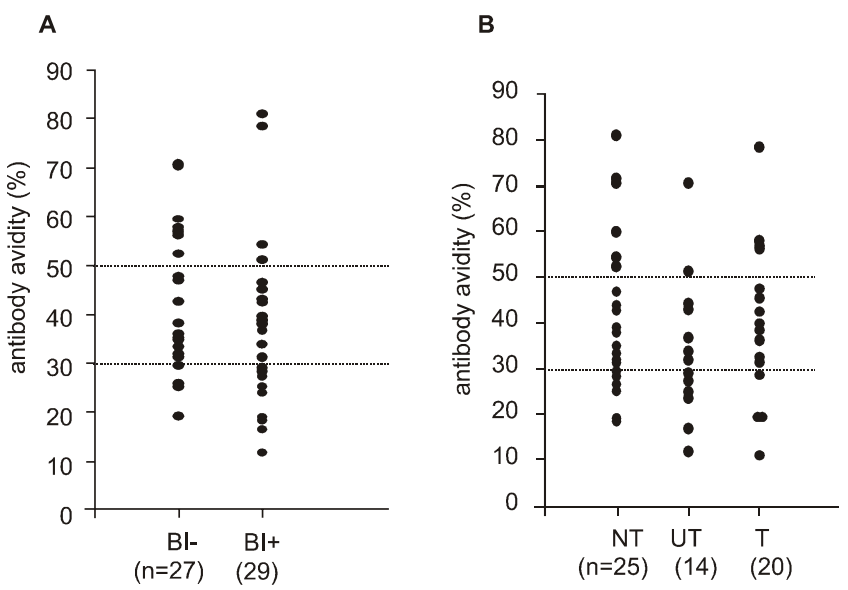

Obs. not treated (NT), under treatment (UT) and treated (T) groups

Table 1. Salivary anti-PGL1 IgM and IgA and serum anti-PGL-1 IgG titers and avidities in leprosy patients

\begin{tabular}{|c|c|c|c|c|c|c|c|}
\hline \multirow{2}{*}{$\begin{array}{l}\text { Sample } \\
\text { number }\end{array}$} & \multicolumn{2}{|c|}{$\begin{array}{l}\text { Salivary antibody titer } \\
\text { (OD }_{405} \text { values) }\end{array}$} & \multicolumn{2}{|c|}{$\begin{array}{l}\text { Anti-PGL-1 antibodies } \\
\text { Serum IgG } \\
\end{array}$} & \multirow[t]{2}{*}{ BI } & \multirow[t]{2}{*}{ Group } & \multirow[t]{2}{*}{ Treatment } \\
\hline & IgM & IgA & Titer & Avidity (\%) & & & \\
\hline 1 & 872 & $\mathrm{n}$ & 4.7 & 59.1 & 3.6 & MB-L & NT \\
\hline 2 & $\mathrm{n}$ & 526 & 2.3 & 25.8 & 0 & BT & NT \\
\hline 3 & 2651 & 1955 & 4.3 & 41.0 & - & MB-L & NT \\
\hline 4 & 2365 & $\mathrm{n}$ & 6.2 & 81.0 & 4.2 & MB-L & NT \\
\hline 5 & 897 & $\mathrm{n}$ & 4.8 & 59.5 & 0 & BT & $\mathrm{NT}$ \\
\hline 6 & 1987 & 985 & 4.2 & 38.3 & 4.25 & MB-L & $\mathrm{T}$ \\
\hline 7 & 575 & $\mathrm{n}$ & 0.2 & - & 2.0 & MB-L & $\mathrm{T}$ \\
\hline 8 & $\mathrm{n}$ & 607 & 3.5 & 78.3 & 1.0 & MB-L & $\mathrm{T}$ \\
\hline 9 & $\mathrm{n}$ & $\mathrm{n}$ & 3.1 & 19.0 & 0 & MB-L & $\mathrm{T}$ \\
\hline- & - & 3.0 & 11.1 & 0 & MB-L & $\mathrm{T}$ & \\
\hline
\end{tabular}

$\mathrm{N}=$ normal values, $\mathrm{NT}=$ not treated, $\mathrm{T}=$ treated, $-=$ not done.

Table 2. Serum anti-PGL-1 IgG avidity in not treated, under treatment and treated leprosy patients with positive titers of anti-PGL IgG. Avidity-antibodies below 30\% have been considered low, while the ones above 50\% are seen high

\begin{tabular}{|c|c|c|c|c|c|c|c|c|c|}
\hline \multirow{3}{*}{ Clinical status } & \multicolumn{9}{|c|}{ Treatment period } \\
\hline & \multicolumn{3}{|c|}{ Not treated $(n=21)$} & \multicolumn{3}{|c|}{ Under treatment (n=15) } & \multicolumn{3}{|c|}{ Treated (n=19) } \\
\hline & $\begin{array}{c}\text { Low } \\
\text { avidity }\end{array}$ & $\begin{array}{c}\text { Medium } \\
\text { avidity }\end{array}$ & $\begin{array}{c}\text { High } \\
\text { avidity }\end{array}$ & $\begin{array}{c}\text { Low } \\
\text { avidity }\end{array}$ & $\begin{array}{l}\text { Medium } \\
\text { avidity }\end{array}$ & $\begin{array}{c}\text { High } \\
\text { avidity }\end{array}$ & $\begin{array}{c}\text { Low } \\
\text { avidity }\end{array}$ & $\begin{array}{l}\text { Medium } \\
\text { avidity }\end{array}$ & $\begin{array}{l}\text { High } \\
\text { avidity }\end{array}$ \\
\hline Paucibacillar & & 1 & 1 & & & & & & \\
\hline Borderline tuberculoid & 2 & 2 & 3 & & & & 1 & 1 & \\
\hline Multibacillar & 4 & 6 & 2 & 5 & 8 & 2 & 2 & 9 & 6 \\
\hline Total (N) & 6 & 9 & 6 & 5 & 8 & 2 & 3 & 10 & 6 \\
\hline
\end{tabular}


(2 out of 23). One of them showed high titers and the other one was in the upper limit of the normal range. We found out that both had a familiar member with leprosy and for this reason they were excluded from the study. None of the normal controls showed positivity for salivary anti-PGL-1 IgM antibodies. We can suppose that IgA isotype is representative of present or past infection and that IgM is probably representative of a present infection. The majority of the samples from leprosy patients showed salivary anti-PGL-1 IgA/IgM levels similar to the normal controls, except the MB-L and some of the BT patients, who presented high levels of antibodies. The absence of mucosal antibodies could suggest that PGL-1 antigen was no longer present in sufficient quantity in mucosal surfaces to induce a local immune response. It is important to remember that the halflife of mucosal IgA and IgM plasma cells in lamina propria is very short, around 5 days. During ontogeny, secretory IgM antibody levels predominate in infants and decrease proportionally to the increase of IgA levels [18-20]. This observation, together with the demonstration that PGL-1 antigenemia disappears from the circulation after 2 weeks of treatment [8], leads to the speculation that the presence of salivary IgM antibodies to PGl-1 is directly correlated to mucosal bacterial load. Therefore, the possibility of detecting salivary IgM reactive to PGL-1 could indicate recent infection or re-infection.

One patient with the polar lepromatous clinical form, who had completed the drug regimen treatment showed very high levels of salivary anti-PGL-1 IgM and IgA, positive bacilloscopy and elevated serum anti-PGL-1 IgG levels (sample number 6, Table 1). We supposed that the patient was being challenged by $M$. leprae at mucosal surfaces and at an internal site, resultant from re-infection or from a reactivation. The main targets of M.leprae infection are the Schwan cells, through a probable mechanism involving an isoform of laminin, called $\alpha 2$-laminin, which is the major constituent of basal lamina, principally in the peripheral nerves and a 21-kd glycoprotein on the surface of $M$. leprae [21]. M. leprae probably gains access to the peripheral nerves through infected blood monocytes from injured skin and mucous membranes which could transport the bacilli through the peripheral nervous system and, when the bacterial load leads to the destruction of the cells, the pathogen would be liberated into the endoneural space [22]. Santos et al. [23] found a high frequency of positive polymerase chain reaction in the blood of patients several years after completion of antileprosy multidrug therapy, suggesting persistent circulating bacilli, although reinfection of these individuals could not be excluded, according to the authors. Under these circumstances, one could expect that low-avidity antibodies are resultant from a recent exposure to the released bacteria. For this reason, we developed in the present work an enzyme-immunoassay for testing avidity of anti-PGL-1 IgG isotype.

The antibody avidity parameter has been used to distinguish recent and chronic infection, considering that low antibody avidity represents acute or recent infection and high antibody avidity, chronic or past infection in some diseases, as toxoplasmosis [24], for instance.
In the present project, the serum samples were exposed to a predetermined molar concentration of potassium thiocyanate (2.0 $\mathrm{M}$ in this case). In our protocol, using normal human serum as a reference for high-antibody avidity, we observed that molarities above $2 \mathrm{M}$ washed out more than $50 \%$ of the complexes. Based on these observations, we decided to choose $2 \mathrm{M}$ as the ideal concentration for testing anti-PGL antibody avidity. Serum samples containing more than $50 \%$ of bound antibodies after KSCN elution were considered to have high antibody avidity, while those containing between $30 \%$ and $49 \%$ of bound complexes after KSCN elution, medium antibody avidity and below 29\%, low antibody avidity.

We found 2 patients with complete drug regimen treatment with very low antibody avidity (samples number 9 and 10, Table 1). One of them (sample number 9 ) had the lepromatous form; she was diagnosed to have neuritis at the time of serum collection and her laboratorial parameters showed negative bacilloscopy, elevated levels of serum anti-PGL-1 IgG with $19 \%$ antibody avidity, and normal salivary anti-PGL titers. Considering that low antibody avidity represents acute infection and that the normal salivary IgM antibodies indicate absence of local bacterial load, we can suppose that the antigenic challenge occurred from an internal site of infection. Bacilloscopy was negative possibly because the sensitivity of the technique was insufficient to detect low quantities of bacteria. The other patient (sample number 10) had the borderline lepromatous clinical form and was diagnosed to have an erythema nodosum reaction at the time of sample collection. The patient showed elevated titers of serum antiPGL-1 IgG with 11\% antibody avidity. Her saliva was not available. If avidity is currently considered to be a functional parameter for distinguishing the time of infection [12,24,25], it is important not to discard the hypothesis that the patient was presenting an immune response to antigens from viable bacteria present in an internal site of infection in very low quantities that no available technique could detect.

Concluding, once IgM antibody is short-lived, we suppose that its persistence in mucosal surfaces depends on local bacterial load. Another point to take in consideration is that the local immune response precedes serum antibody production and this observation could be useful for epidemiological purposes. Besides this parameter, antibody avidity could be associated to the bacilloscopy index and to serum anti-PGL IgG levels as antibody avidity status is actually used for indicating recent exposure or re-exposure to various infectious diseases.

\section{Acknowledgement}

This research was supported by the Ministério da Saúde/ DECIT/SESA-Ceará.

\section{References}

1. Naafs B. Viewpoint: Leprosy after the year 2000. Trop Med Intern Health 2000;5:400-3. 
2. Abulafia J., Vignale R.A. Leprosy: accessory immune system as effector of infectious, metabolic and immunologic reactions. Int J Dermatol 2001;40:673-87.

3. Almeida E.C., Martinez A.N., Maniero V.C., et al. Detection of Mycobacterium leprae DNA by polymerase chain reaction in the blood and nasal secretion of Brazilian household contacts. Mem Inst Oswaldo Cruz 2004;99:509-512.

4. Sinha S., Kannan S., Nagarau B., et al. Utility of serodiagnostic tests for leprosy: a study in an endemic population in South India. Lepr Rev 2004;75:266-73.

5. Davey T.F., Rees R.J. The nasal discharge in leprosy: clinical and bacteriological aspects. Lepr Rev 1974;45:121-34.

6. Near K.A., Lefford M.J. Use of serum antibody and lysozyme levels for diagnosis of leprosy and tuberculosis. J Clin Microbiol 1992;30:1105-10.

7. Rojas R.E., Segal-Eiras A. Characterization of circulating immune complexes in leprosy patients and their correlation with specific antibodies against Mycobacterium leprae. Clin Exp Dermatol 1997;22:223-39.

8. Cho S.N., Cellona R.V., Villahermosa L.G., et al. Detection of phenolic glicolypid I of Mycobacterium leprae in sera from leprosy patients before and after start of multidrug therapy. Clin Diagn Lab Immunol 2001;8:138-42.

9. Cho S.-N., Yanagihara D.L., Hunter S.W., et al. Serological specificity of phenolic glycolipid 1 from Mycobacterium leprae and use in serodiagnosis of leprosy. Infect Immun 1983;41:1077-83.

10. Brandtzaeg P. Molecular and cellular aspects of the secretory immunoglobulin system. APMIS 1995;103:1-19.

11. Hanson L.A., Dahlman-Hoglund A., Karlsson M., et al. Normal microbial flora of the gut and the immune system. In: Probiotics, Other Nutritional Factors, and Intestinal Microflora, Nestlé Nutrition Workshop Series. (Hanson LA, Yolken H, eds), Philadelphia: Vevey/ Lippincott-Raven Publishers, 1999:217-28.

12. Woznicova V. Immunoglobulin G avidity in infectious diseases. Epidemiol Mikrobiol Immunol 2004;53:4-11.

13. Gutierrez J., Maroto C. Are IgG antibody avidity assays useful in the diagnosis of infectious diseases? A review. Microbios 1996;87:113-21.
14. Ridley D.S., Jopling W.H. Classification of leprosy according to immunity. A five-group system. Int J Lepr 1966;34:255-73.

15. Jones C.L., Macdonald R.A., Hosking C.S., et al. Estimating the relative avidity of mucosal IgA for antigen. J Immunol Methods 1987;105:111-17.

16. Holmgren J., Rudin A. Mucosal immunity and bacteria. In: Mucosal Immunology. (Ogra PL et al., eds.), $2^{\text {nd }}$ edn, London: Academic Press Ltd., 1999:685-93.

17. Smith W.C., Smith C.M., Cree I.A., et al. An approach to understanding the transmission of Mycobacterium leprae using molecular and immunological methods: results from the MILEP2 study. Int J Lepr Other Mycobact Dis 2004;72:31719.

18. Salvi S., Holgate S.T. Could the airway epithelium play an important role in mucosal immunoglobulin A production? Clin Exp Alergy 1999;29:1597-605.

19. Goldblum R.M., Hanson L.A., Brandtzaeg P. The mucosal defense system. In: Immunologic disorders in infants and children. (Stiehm ER, ed.), $4^{\text {th }}$ edn, Philadelphia: WB Saunders Co, 1996:159-97.

20. Marcotte H., Lavoie M.C. Oral microbiology ecology and the role of salivary immunoglobulin A. Microbiol Molec Biol Rev 1998;62:71-109.

21. Shimon Y., Ng V., Matsumura K., et al. A 21-kDa surface protein of Mycobacterium leprae binds peripheral nerve laminin-2 and mediates Schwann cell invasion. Proc Natl Acad Sci 1999;96:9857-62.

22. Haimanot R.T., Melaku Z. Leprosy. Curr Opin Neurol 2000;13:31722.

23. Santos A.R., Balassiano V., Oliveira M.L.W., et al. Detection of Mycobacterium leprae DNA by polymerase chain reaction in the blood of individuals, eight years after completion of antileprosy therapy. Mem Inst Oswaldo Cruz 2001;96:1129-33.

24. Tanyuksel M., Guney C., Araz E., et al. Performance of the immunoglobulin $G$ avidity and enzyme immunoassay IgG/IgM screening tests for differentiation of a clinical spectrum of toxoplasmosis. J Microbiol 2004;42:211-5.

25. Andrews J.I., Diekema D.J., Yankowitz J. Prenatal testing for infectious diseases. Clin Lab Med 2003;23:295-315. 